\title{
Towards a Reactive Power Oscillation Damping Controller for Wind Power Plant Based on Full Converter Wind Turbines
}

\author{
Knüppel, Thyge; Kumar, Sathess; Thuring, Patrik; Støttrup, Michael ; Friman, Johan
}

Published in:

2012 IEEE Power \& Energy Society General Meeting

Link to article, DOI:

10.1109/PESGM.2012.6345317

Publication date:

2012

Link back to DTU Orbit

Citation (APA):

Knüppel, T., Kumar, S., Thuring, P., Støttrup, M., \& Friman, J. (2012). Towards a Reactive Power Oscillation Damping Controller for Wind Power Plant Based on Full Converter Wind Turbines. In 2012 IEEE Power \& Energy Society General Meeting IEEE. https://doi.org/10.1109/PESGM.2012.6345317

\section{General rights}

Copyright and moral rights for the publications made accessible in the public portal are retained by the authors and/or other copyright owners and it is a condition of accessing publications that users recognise and abide by the legal requirements associated with these rights.

- Users may download and print one copy of any publication from the public portal for the purpose of private study or research.

- You may not further distribute the material or use it for any profit-making activity or commercial gain

- You may freely distribute the URL identifying the publication in the public portal 


\title{
Towards a Reactive Power Oscillation Damping Controller for Wind Power Plant Based on Full Converter Wind Turbines
}

\author{
Thyge Knüppel, Sathees Kumar, Patrik Thuring, Michael Støttrup, Johan Friman
}

\begin{abstract}
In this paper a power oscillation damping controller (POD) based on modulation of reactive power ( $\triangle Q$ POD) is analyzed where the modular and distributed characteristics of the wind power plant (WPP) are considered. For a $\Delta Q$ POD it is essential that the phase of the modulated output is tightly controlled to achieve a positive damping contribution. It is investigated how a park level voltage, reactive power, and power factor control at different grid strengths interact with the $\Delta Q$ POD in terms of a resulting phase shift. A WPP is modular and distributed and a WPP $\triangle Q$ POD necessitate that each WT contributes to a collective response. This ability is shown with a 150 wind turbine (WT) WPP with all WTs represented, and it is demonstrated that the WPP contributes to the inter-area damping. The work is based on a nonlinear, dynamic model of the 3.6 MW Siemens Wind Power WT.
\end{abstract}

Index Terms - wind turbines, wind power plant, wind power plant controller, power oscillation damping controller (POD), power systems, small-signal stability

\section{INTRODUCTION}

$\mathbf{W}$ ITH increased penetration of wind turbines (WT) and wind power plants (WPP) it is important to understand how these units interact with and affect phenomena associated with power system stability. Regarding power system oscillations, several studies have investigated the impact of wind power on power system oscillations [1]-[4].

The controllable active and reactive power output of a WPP based on converter interfaced WTs means that by proper control, the WPP output can be modulated to increase the system damping to power oscillations. It has been suggested in a number of recent publications to equip WTs with a power oscillation damping controller (POD) for either active power modulation ( $\triangle P$ POD) [5]-[9], reactive power modulation ( $\Delta Q$ POD) [8], [10], [11], or a combination of both [12]. The impact of reduced inertia is studied in [13] and it is found that a control proportional to frequency deviation had a positive damping contribution. In [8], the torsional drive train mode is analyzed for a doubly fed induction generator (DFIG) for both $\triangle P$ and $\triangle Q$ POD and it is found that the $\triangle P$ POD can destabilize this mode, while this mode seemed immune to the $\Delta Q$ POD. The presence of WT mechanical resonance frequencies within the typical range for power system oscillations may limit the frequency range in which a particular WT

T. Knüppel is with Siemens Wind Power A/S, DK-7330 Brande, Denmark and Centre for Electric Technology, Department of Electrical Engineering, Technical University of Denmark, DK-2800 Lyngby, Denmark (thyge.knuppel@siemens.com)

S. Kumar, P. Thuring, M. Støttrup, and J. Friman are with with Siemens Wind Power A/S, DK-7330 Brande, Denmark can participate with $\Delta P$ modulation, since the feasibility of a $\Delta P$ POD requires that it can be operated without exciting oscillations at mechanical resonance frequencies.

In [14] the modular and distributed characteristics of a WPP were included and the results indicate that a central WPP POD is possible for both active and reactive power modulation.

It is well-known that power oscillation damping may be increased from proper reactive power modulation of FACTS devices [15] and this ability is in practice utilized by transmission system operators [16]. It is, however, also recognized that FACTS devices are generally less robust against changes in the operating condition than synchronous machine power system stabilizers (PSS) [15]. Therefore, optimal siting for FACTS units and optimal choice of control signals are tasks that have been widely treated in the literature as e.g. [17]-[20]. Robust control and optimization methods have also been proposed to enhance the robustness towards changing operating conditions, control interactions, time delay uncertainties, e.g. [21]-[23]. A comprehensive review of robust control applications for power system studies is presented in [24]. In [25], [26] a combination of a discontinuous bang-bang control and a low gain continuous controller are proposed to avoid interactions with other stabilizing controllers. For a WPP $\triangle Q$ POD many of the considerations for FACTS devices would also apply, although the siting may already be decided by other factors such as wind resources and access to the transmission grid.

Although it has previously been shown that a WPP equipped with a $\triangle Q$ POD can contribute positively to the damping of power system oscillations, many aspects of a $\Delta Q$ POD still remain to be understood. The published studies have dealt with very simplified WPP models using an aggregate WT model, which do not consider that the WTs within a feeder do not necessarily have the same reactive capacity available for reactive power modulation. Large WPPs are routinely equipped with park level voltage, reactive power, or power factor controllers that coordinate the response of the WTs to regulate at a specific bus, and the interaction between these park level controllers and the $\Delta Q$ POD remains to be analyzed.

First in section II, factors influencing the resulting phase shift of a $\triangle Q$ POD in a WPP are investigated. Secondly in section III, a WPP including a $\Delta Q$ POD is simulated where all the WTs are represented individually to assess the capability of the WTs to execute the commanded reactive power modulation. Finally, the discussion and the conclusion are found in section IV and V, respectively. 


\section{Phase Control of $\Delta Q$ POD}

The damping of a selected eigenvalue is improved by modulation of the WPP reactive power output where the modulated output power has a certain phase shift with respect to the input signal that contains the oscillation. To have a positive damping contribution it is, thus, necessary to tightly control the phase of the oscillating reactive power. The ability of the WPP to track this phase depends among other things on 1) the interaction between the $\Delta Q$ POD and WPP level voltage, reactive power, and power factor controls, 2) the speed of WPP and WT responses, and 3) the strength of the grid. To evaluate the need for phase compensation for a typical WPP, the phase shift induced from the WT voltage control and from the WPP voltage, reactive power, and power factor controls are considered in section II-C and II-D, respectively.

\section{A. Wind Power Plant Model}

An aggregate WPP model is used for this part of the study, since the scope is the interaction between the grid and the WPP. A single-line diagram of the system is shown in Fig. 1 where an equivalent collector grid connects the upscaled WT to the park transformer, and where the external grid is modeled as a voltage source and an impedance with a given short-circuit ratio (SCR).

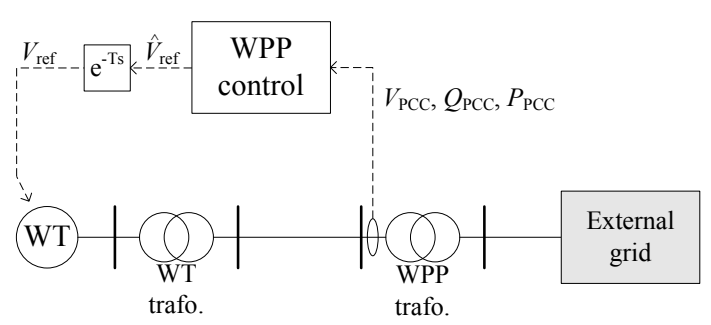

Fig. 1. Single-line diagram of the single machine infinite bus system used for the analysis in section II

The WPP is equipped with a park level controller for voltage, reactive power, or power factor control, which at the point of common connection (PCC) measures the voltage, $V_{\mathrm{PCC}}$, the reactive power flow, $Q_{\mathrm{PCC}}$, and the active power flow, $P_{\mathrm{PCC}}$. In Fig. 1 the PCC is placed on the low voltage side of the WPP transformer but could also have been placed elsewhere, as e.g. the high voltage side of the transformer. For this study a continuous time park level controller is used and issues related to the speed of the controller have, thus, not been considered. However, for a digital controller with a certain sample rate, it is important to evaluate the frequencies at which a meaningful control can be designed.

A transmission delay of $50 \mathrm{~ms}$ is considered between the WPP controller and the WTs to account for processing time at both WPP and WT level as well as the actual transmission time from the WPP to the WTs.

\section{B. Wind Turbine Model}

The WPP is represented by a single upscaled WT model that is operated in voltage control mode. The WT concept for this study is a variable-speed, pitch controlled, full converter interfaced WT. The WT is represented with a reduced order model suitable for transient and dynamic power system studies. The model represents a 3.6 MW Siemens Wind Power WT [27]. The model includes a variable wind speed aerodynamic model, a two-mass model of rotor, gearbox, and generator, machine and grid side converter, DC-link, and a generic reduced order control scheme.

\section{Phase Shift by Grid Strength}

The voltage control of the WT tracks the desired terminal voltage reference by control of the reactive current output. Intuitively, the strength of the grid at the PCC determines the amount of required reactive current to track the voltage reference, where a higher current is needed for the same change in terminal voltage for the stronger grid. For $\Delta Q$ POD operation, where the WT voltage controller receives an oscillating reference, the inability of the voltage controller to track the reference results in the terminal voltage that is lagging the reference.

To illustrate this, consider the circuit diagram in Fig. 2, which is a simplified representation of the setup in Fig. 1 with the $\triangle Q$ POD being the only WPP control in service. For simplicity only the top level WT voltage control, $C(s)$, is shown.

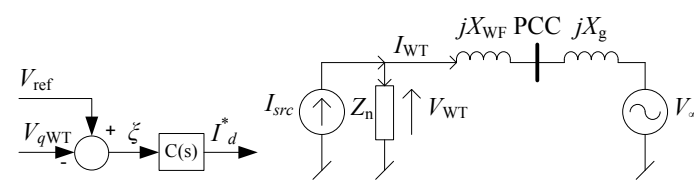

Fig. 2. Simplified circuit of the WPP with only the reactive WT control considered.

The ability of the voltage controller, $C(s)$, to track the voltage reference, $V_{\text {ref }}$, is analyzed by means of the transfer function between the voltage reference, $V_{\text {ref }}$, and infinite bus voltage, $V_{\infty}$, to the terminal voltage, $V_{\mathrm{WT}}$, which is shown in (1). The transfer function is given by the network equations and the block diagram in Fig. 2. If the $q$ axis of the $d q$ coordinate system is aligned with $V_{\mathrm{WT}}$, the transfer function may be derived as

$$
\begin{aligned}
V_{q \mathrm{WT}}= & T_{1}(s) V_{\mathrm{ref}}+T_{2}(s) V_{q \infty} \\
= & \frac{C(s)}{\frac{1}{X_{\mathrm{WF}}+X_{g}}+\frac{X_{n}}{\left|Z_{n}\right|^{2}}+C(s)} V_{\mathrm{ref}} \\
& +\frac{1}{\left(X_{\mathrm{WF}}+X_{g}\right)\left(C(s)+\frac{X_{n}}{\left|Z_{n}\right|^{2}}\right)+1} V_{q \infty} .
\end{aligned}
$$

Ideally $T_{1}(s)=1$ in (1) which would imply perfect tracking of $V_{\text {ref }}$ for all frequencies, and from the derived expression in (2) it is, thus, possible to investigate factors that influence the tracking ability of the WT voltage control. For a common WPP installation $X_{g} \gg X_{\mathrm{WF}}$ and from (2) it is clear that as the SCR increases, i.e. $X_{g}$ decreases, the ability to track the reference reduces.

In Fig. 3 the expression in (2) is compared with a detailed model of the system in Fig. 1 for a sweep of network SCRs. 
From the comparison it is seen that the simple representation in (2) captures the dominant dynamics of the system, although the results are seen to be more conservative than the detailed model. For frequencies above $1 \mathrm{~Hz}$ the phase response for the simple representation starts to deviate from the phase response of the detailed model.
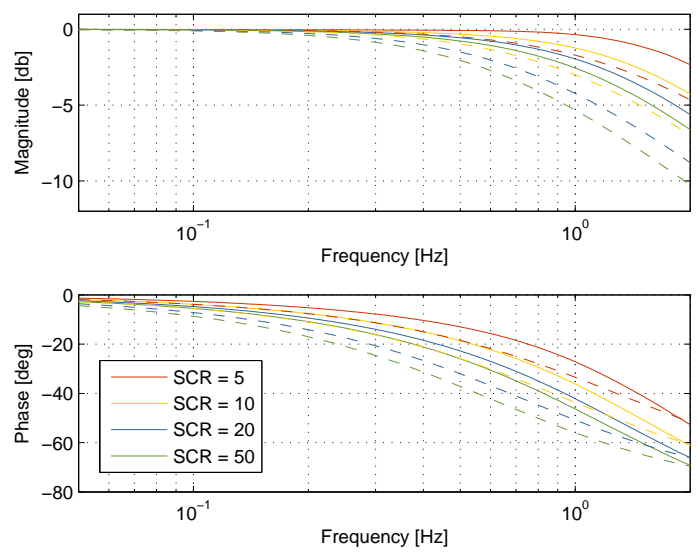

Fig. 3. Dependency of phase shift induced by WT voltage controller to the strength of the grid. Solid lines: detailed model, dashed lines: simplified model.

\section{Phase Shift by Park Level Voltage, Reactive Power, and Power Factor Control}

The objective of a WPP voltage, reactive power, and power factor control is to coordinate the response of the individual WTs to achieve a certain condition at a remote bus, i.e. typically at the PCC, as schematically illustrated in Fig. 1. For a $\Delta Q$ POD this adds an additional feedback path from the modulated reactive power output at the WT, through the collector grid, the WPP voltage, reactive power, or power factor control, and an updated voltage reference signal. Evidently, this feedback has the potential of changing the phase of the modulated reactive power output if the bandwidth of the controllers overlap. The speed of the WPP voltage control is determined by the grid code requirements where the UK grid code requires that $90 \%$ of the pre-disturbed value is delivered within 1 second [28]. Such response time is clearly within the range of the low frequency power system oscillations.

As an example, the block diagram of a WPP voltage control is shown in Fig. 4 where also two input candidates for the $\Delta Q$ POD reference signal are shown. For the WPP voltage controller, input $1, V_{\mathrm{POD} 1}$, corresponds to a tracking problem whereas input $2, V_{\mathrm{POD} 2}$, corresponds to a disturbance that should be rejected. The general structure in Fig. 4 is also used for the WPP reactive power control and the power factor control where the error calculation, $\xi$, in each case have been appropriately modified.

The transfer function between the $\Delta Q$ POD output and the voltage reference received at the WT, $\frac{V_{\text {ref }}(s)}{V_{\operatorname{POD}}(s)}$, is in Fig. 5 and 6 evaluated for, respectively, $V_{\mathrm{POD} 1}$ and $V_{\mathrm{POD} 2}$ as input. Frequency responses are shown for both WPP voltage control, reactive power control, and power factor control, and the responses have been evaluated for a sweep of SCRs. The

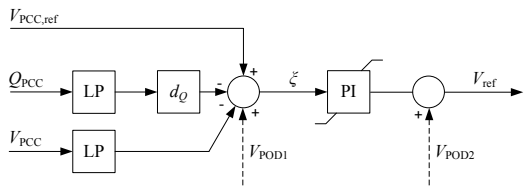

Fig. 4. Block diagram of WPP voltage droop controller with two possible input connections for the $\triangle Q$ POD.

frequency responses are only shown for a single parameter set for each controller, but it is clear that the tuning of the controllers will impact the resulting frequency responses. In both Fig. 5 and 6 the frequency responses for reactive power and power factor control overlap and it is not possible to distinguish between the curves for these controllers. The frequency response for the voltage control is fundamentally different from that of the reactive power and power factor control. For frequencies below $1 \mathrm{~Hz}$, reactive power control and power factor control show a response that varies for different SCRs, whereas much less variation is noted using voltage control. For higher frequencies, i.e. $>1 \mathrm{~Hz}$, the transmission delay dominates the phase response with an increasing phase lag.
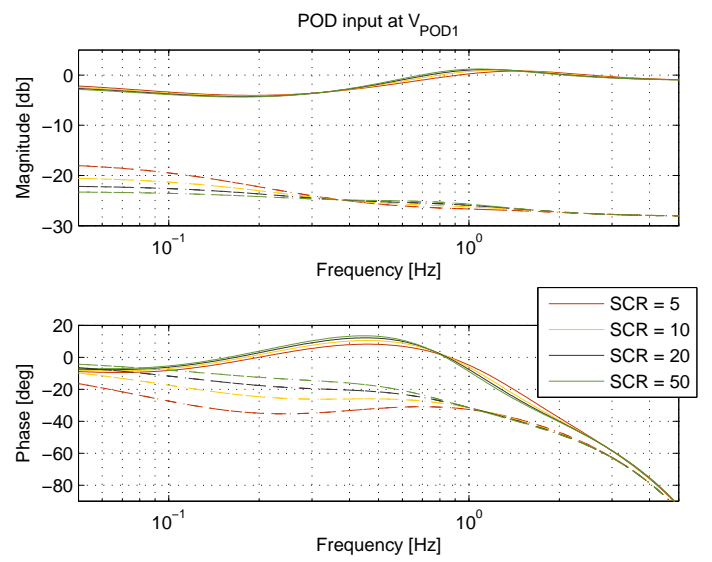

Fig. 5. Induced phase shift in WT voltage reference signal by WPP voltage or reactive power control for an input at $V_{\mathrm{POD} 1}$. Solid: voltage control, dashed: reactive power control, dash dotted: power factor control. Note that the curves for reactive power and power factor control overlap.

For the tracking control in Fig. 5 it is seen that the phase response for the voltage control has a variation of $\pm 15^{\circ}$ around $0^{\circ}$. The reactive and the power factor control has for SCRs $\geq 10$ a constant and increasing phase lag for increasing frequencies of oscillation. The large difference in magnitude is due to the different units used internally in the controllers.

A similar response is found for all three WPP controllers when the $V_{\mathrm{POD} 2}$ input is used, cf. Fig. 6. For low frequencies the WPP control is sufficiently fast to cancel much of the $\Delta Q$ POD response with a resulting large phase shift and a low gain.

\section{Case Study With Detailed WPP}

Successful operation of the WPP $\Delta Q$ POD requires that the WTs within the unit are capable of executing the commanded reactive power modulation and that the WTs respond to give 

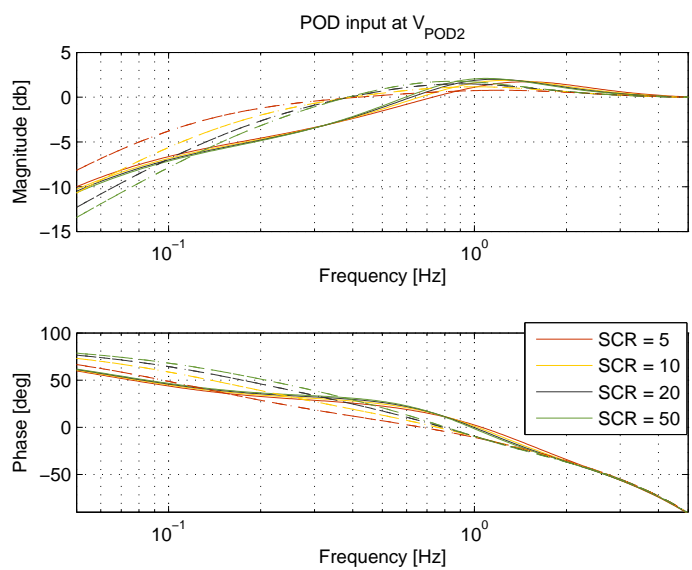

Fig. 6. Induced phase shift in WT voltage reference signal by WPP voltage or reactive power control for an input at $V_{\mathrm{POD} 2}$. Solid: voltage control, dashed: reactive power control, dash dotted: power factor control. Note that the curves for reactive power and power factor control overlap.

a collective WPP response. The distributed nature of a WPP means that the control of one WT interacts with the control of the other WTs and it is important to evaluate how this interaction affects the collective WPP response. Additionally, the distributed nature means that the WTs might be in different steady state operating points.

Clearly, an analysis as indicated above requires the use of a detailed WPP model with the WTs represented individually. The study is performed with PSS $\cap$ NETOMAC [29].

\section{A. Network Model}

This part of the study is based on the benchmark power system developed by Gibbard and Vowles [30] to have a system with a complex oscillatory pattern. The synchronous generators within the 14 power stations are here represented individually and all generators are equipped with standard IEEE STAB1 PSSs that have been tuned for weakly damped oscillations between the five areas. The single-line diagram is given in Fig. 7.

In area 2 a 540 MW WPP is connected at bus 212 through a $100 \mathrm{~km}$ transmission line. A short-circuit analysis showed a $\mathrm{SCR} \simeq 10$ at bus 212 . The load and the generator dispatch are given by the "heavy load" scenario in [30] with a total demand of $22300 \mathrm{MW}$ and a combined generation of $23030 \mathrm{MW}$. The production from the WPP is compensated locally in area 2 to maintain the power flow between the areas as described in this scenario.

\section{B. Wind Power Plant Model}

The WPP consists of 150 3.6 MW WTs that are represented individually and distributed over 19 feeders, three park transformers, and where the PCC is defined as the high voltage side of the park transformers. The interconnection to the network is shown in Fig. 7 and the single-line diagram of the WPP layout in Fig. 8. A more detailed description of the WPP model with cable and transformer parameters are given in [14].

Each WT is represented by the model described in section II-B and a WPP voltage controller as shown in Fig. 4 is

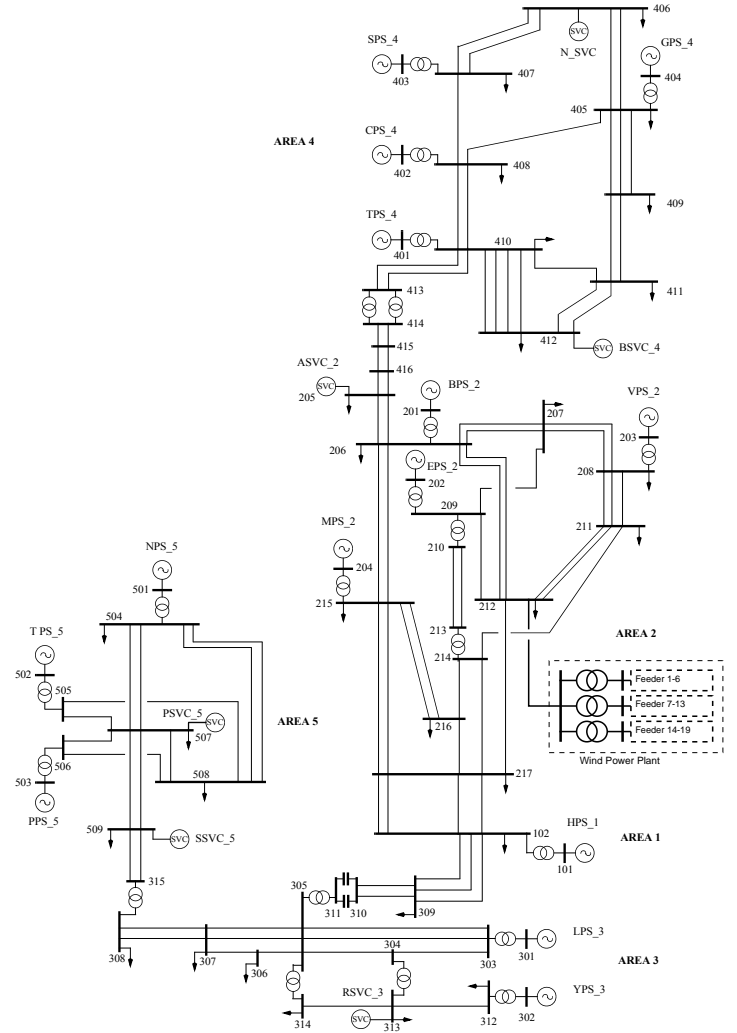

Fig. 7. Single-line diagram of the studied power system [30]

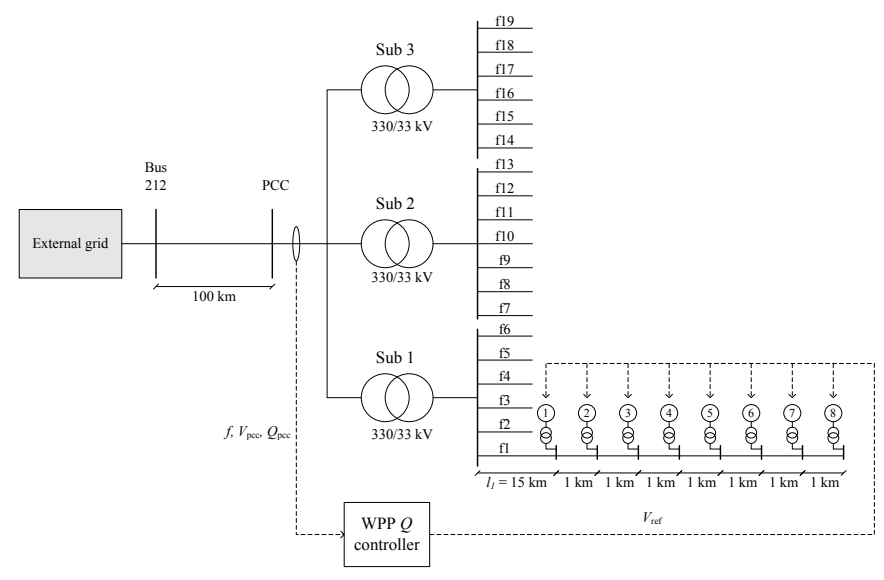

Fig. 8. Single-line diagram of the WPP layout used in the analysis.

connected to the unit, to which a $\Delta Q$ POD is interfaced at input $V_{\mathrm{POD} 1}$. In Fig. 8, the block "WPP $Q$ controller" includes both WPP voltage control, WPP $\triangle Q$ POD, and a transmission and processing delay as discussed in section II-A. The $\Delta Q$ POD loop is defined as

$$
G_{\mathrm{POD}}(s)=K \frac{s T_{w o}}{s T_{w o}+1} \frac{1}{s T_{l p}+1} G_{p c}(s)
$$

where $K$ is the gain, $T_{w o}$ is the wash-out filter time constant, $T_{l p}$ the low-pass filter time constant, and where $G_{p c}(s)$ is the transfer function for the phase compensation. The $\Delta Q$ POD is driven by the PCC frequency, which is here synthesized by the 
time derivative of the PCC voltage angle using $\frac{s}{s 0.03+1}$, and the output is limited to $\Delta V_{\mathrm{POD}}=0.05 \mathrm{pu}$ and the transmitted voltage reference is here limited to $V_{\text {ref }}=1.08 \mathrm{pu}$.

\section{Simulation Results}

A distant $50 \mathrm{~ms}$ three-phase short-circuit at bus 307 is used to excite oscillations between the five system areas. A base case is, furthermore, simulated where the $\Delta Q$ POD is disabled. The transfer function for the phase compensation, $G_{p c}(s)$, is designed with classical residue analysis and is designed for a PCC voltage of $0.99 \mathrm{pu}$, which corresponds to nominal terminal voltage of the WTs, i.e. $1.00 \mathrm{pu}$.

1) WPP Characteristics: The modal characteristics of the analyzed system in terms of the frequency, $f$, and the damping ratio, $\zeta$, of the dominant oscillations are shown in TABLE I and plotted in Fig. 9. The frequencies and damping ratios in TABLE I have been computed with Prony analysis of the speed of $G_{1}$ at the $\mathrm{NPS}_{5}$ power station in area 5. The oscillations described by $\lambda_{1-2}$ are global with all the areas participating, whereas $\lambda_{3}$ is contained mainly within area 3 and $\lambda_{4}$ mainly has participation from area 1 and 2. From TABLE I and Fig. 9 it is seen that the damping ratios for $\lambda_{1,2,4}$ increase with the $\Delta Q$ POD in operation, whereas the damping ratio for $\lambda_{3}$ is unchanged.

TABLE I

MODAL CHARACTERISTICS OF THE DOMINANT OSCILLATIONS, $\lambda_{1-4}$ COMPUTED WITH PRONY ANALYSIS. THE INDEX OF $f$ AND $\zeta$ REFERS TO THE FOUR SELECTED EIGENVALUES.

\begin{tabular}{l|c|c} 
& no POD & $\Delta Q$ POD \\
\hline$f_{1}[\mathrm{~Hz}]$ & 0.524 & 0.527 \\
$\zeta_{1}[-]$ & 0.019 & 0.022 \\
\hline$f_{2}[\mathrm{~Hz}]$ & 0.346 & 0.347 \\
$\zeta_{2}[-]$ & 0.063 & 0.102 \\
\hline$f_{3}[\mathrm{~Hz}]$ & 1.056 & 1.065 \\
$\zeta_{3}[-]$ & 0.013 & 0.013 \\
\hline$f_{4}[\mathrm{~Hz}]$ & 1.561 & 1.571 \\
$\zeta_{4}[-]$ & 0.021 & 0.023 \\
\hline
\end{tabular}

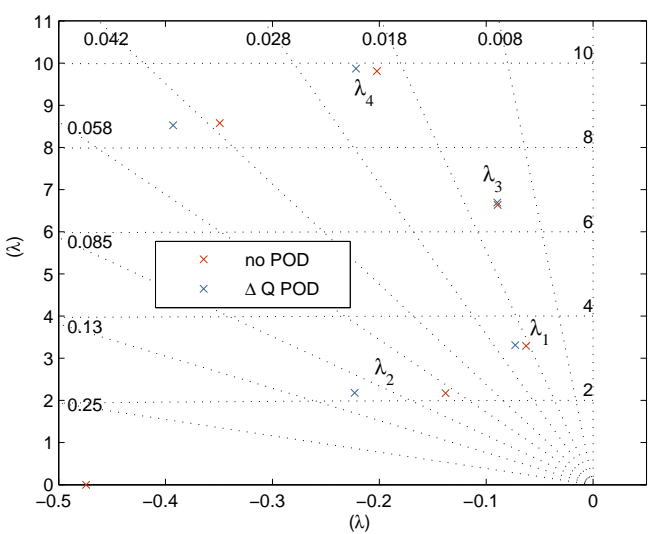

Fig. 9. Complex plane with eigenvalues extracted by Prony analysis of the speed response of $G_{1}$ at the $\mathrm{NPS}_{5}$ power station.
The control action of the $\Delta Q$ POD is shown in Fig. 10 together with the synthesized frequency measurement and the resulting voltage reference, which is finally transmitted to the WTs. From the frequency measurement and from the speed of a dominant generator in each area, shown in Fig. 11, an increased mode damping is noted when the $\Delta Q$ POD is in operation.

When no POD is in operation only minor oscillations are noted in $V_{\text {ref }}$, which stem from the response of the WPP voltage controller to the voltage oscillations induced by the applied disturbance.
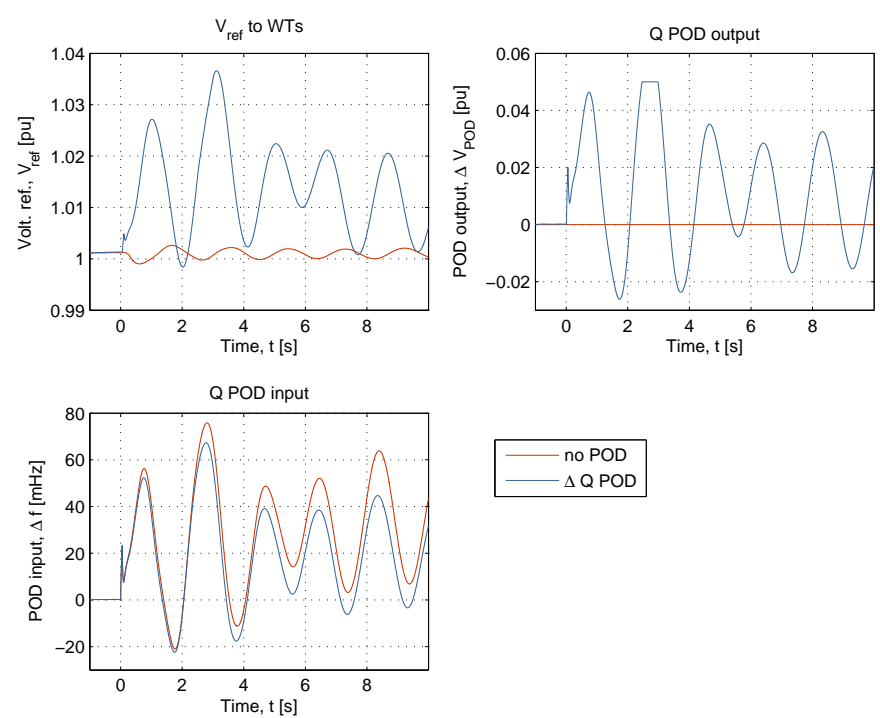

Fig. 10. Input and output signals of the WPP control during a distant treephase short-circuit.

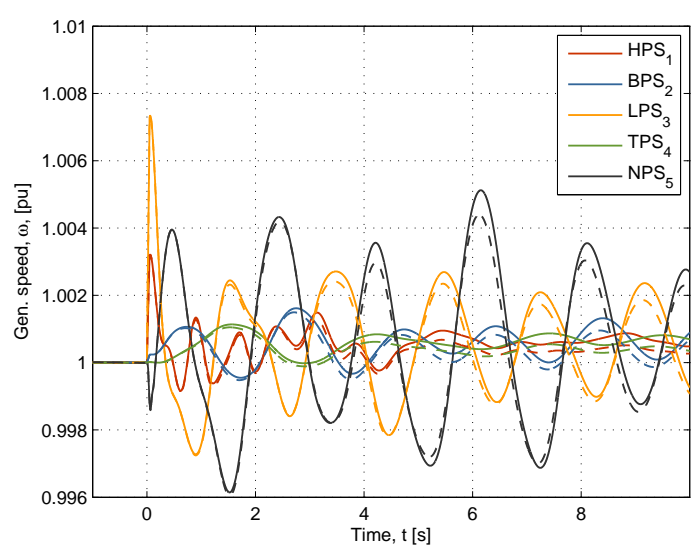

Fig. 11. Impact of $\Delta Q$ POD operation during a distant three-phase shortcircuit on the speed of selected synchronous generators. The results are shown for different PCC steady state voltages. Solid: no WPP POD, dotted: $\Delta Q$ POD.

The reactive power transfer and the bus voltage at the PCC are shown in Fig. 12 for the applied disturbance. It is interesting to observe that the PCC voltage oscillates in almost counter phase when comparing the case with and without the $\triangle Q$ POD in operation.

2) WT Characteristics: The terminal voltage and the reactive power output are shown for eight WTs in Fig. 13 and 14, 


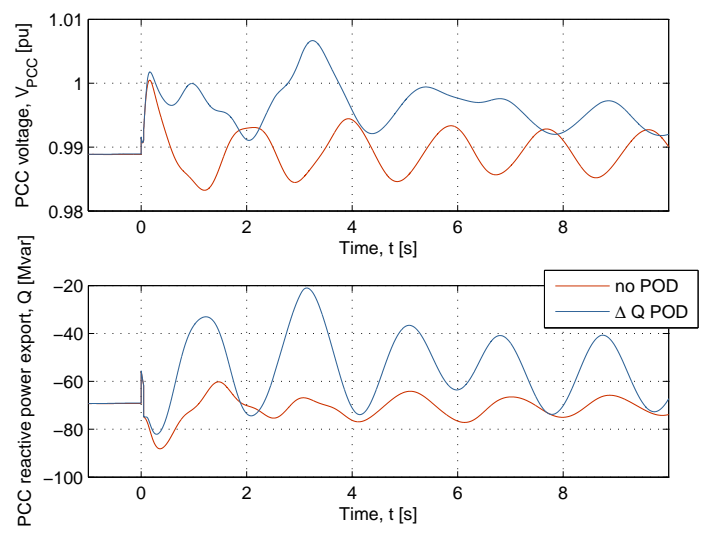

Fig. 12. Impact of $\Delta Q$ POD operation during a distant three-phase shortcircuit on the PCC voltage and reactive power transfer.

respectively. The WTs are the first and the last WT in three selected feeders, which are characterized by the distance of the first WT to the PCC, $l_{1}$, and number of connected WTs, $N_{\text {WT }}$

1) short distance: $l_{1}=1 \mathrm{~km}, N_{\mathrm{WT}}=9, \mathrm{WT}_{80-88}$, and

2) medium distance: $l_{1}=15 \mathrm{~km}, N_{\mathrm{WT}}=8, \mathrm{WT}_{1-8}$,

3) long distance: $l_{1}=20 \mathrm{~km}, N_{\mathrm{WT}}=7, \mathrm{WT}_{127-133}$.

From the WT terminal voltages shown in Fig. 13, it is seen that the responses of the individual WTs are very similar in both magnitude and phase. In the presented simulation, the interaction between the WTs within the WPP therefore does not hinder the WTs in tracking the received voltage reference.
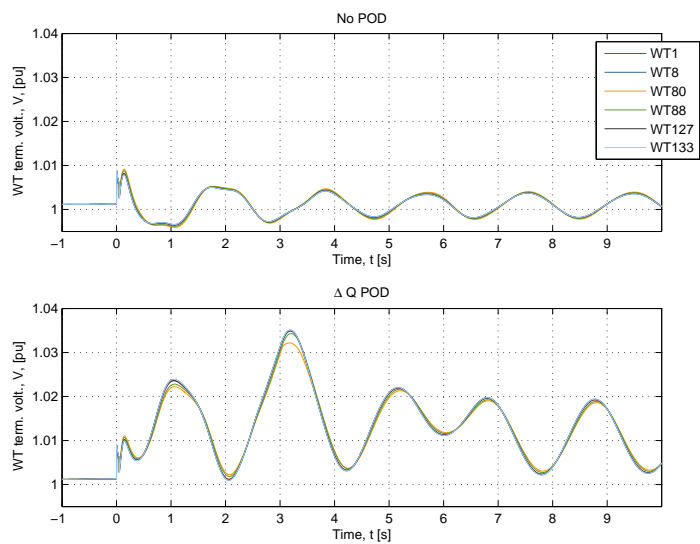

Fig. 13. Selected WT terminal voltage magnitude during a distant three-phase short-circuit with and without the $\triangle Q$ POD in operation.

The reactive power output of the selected WTs is shown in Fig. 14 with and without the $\triangle Q$ POD in operation. The different steady state starting points for the WTs are clearly noted from Fig. 14 where $\mathrm{WT}_{80}$ is exporting reactive power, $\mathrm{WT}_{8,133}$ are importing reactive power, and $\mathrm{WT}_{1,88,127}$ are close to unity power factor. With the $\Delta Q$ POD in operation, an increased reactive power modulation is noted at a lagging phase compared to the pure voltage control response. This is as demanded by the $\Delta Q$ POD.

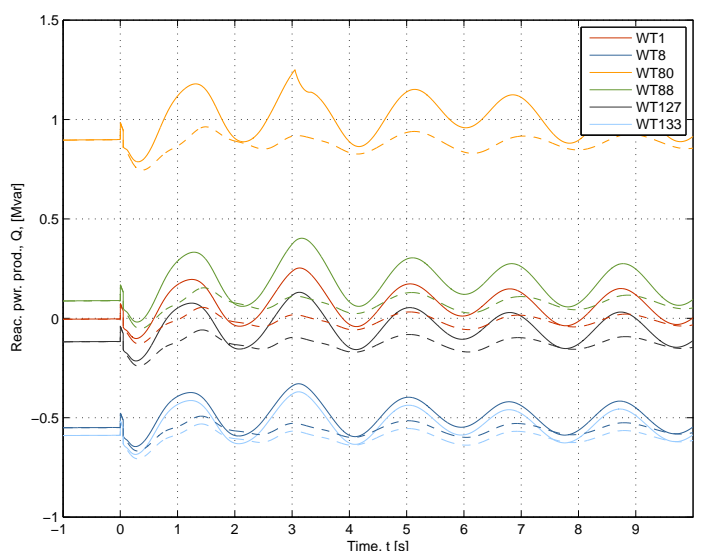

Fig. 14. Selected WT reactive power outputs during a distant three-phase short-circuit with and without the $\triangle Q$ POD in operation. Dashed: no $\Delta Q$ POD, solid: $\triangle Q$ POD.

\section{DISCUSSION}

A continuous power oscillation damping controller (POD) induces a damping torque by demanding a scaled and phase shifted response with respect to a measured input signal with good observability of the eigenvalue(s) to be damped. This study has analyzed the potential use of a park level reactive power POD ( $\triangle Q$ POD) for wind power plants (WPP) with full converter wind turbines (WT).

On both WT and WPP level it is analyzed how existing control structures respond to an oscillating voltage reference to assess the frequency dependency of the resulting phase shift of the oscillation through a WPP.

Today, WPPs are routinely fitted with park level voltage, reactive power, or power factor controllers that coordinate the responses of the WTs to give a combined WPP response. With current requirements for voltage control, the bandwidth of a typical WPP voltage control is within the frequency range of interest for power system oscillations, which means that the interaction between the controllers needs to be considered. The $\Delta Q$ POD is analyzed where it is considered as either a reference tracking problem or a disturbance rejection problem as presented in Fig. 5 and 6, respectively. The analysis showed that the reference tracking input had the most steady characteristic in terms of both magnitude and phase and this input was subsequently used when the $\Delta Q$ POD was analyzed with time domain simulations.

The short-circuit ratio (SCR) at the point of common connection (PCC) is important with respect to both the stiffness of the voltage and the ability of the WT voltage controller to track a given oscillating voltage reference. A low SCR increases the voltage and reactive power oscillations that the WPP can induce when subject to an oscillating voltage reference and therefore increases the feedback gain through the WPP voltage controller to the $\triangle Q$ POD output. For a WPP voltage controller the impact of the SCR is found to be small, whereas a larger impact is found for the analyzed reactive power and power factor controller for frequencies below $1 \mathrm{~Hz}$. A high SCR on the other hand, implies that the terminal voltage of the WT is difficult to change and, 
hence, that the WT voltage controller has difficulties tracking the oscillating voltage reference, which results in a phase lag with respect to the reference, cf. Fig. 3.

Based on frequency analysis, a WPP $\Delta Q$ POD was designed for a 150 WT WPP with all WTs represented individually. Generally, a $\Delta Q$ POD necessitate that sufficient margin is available for the reactive power modulation if a two sided response is requested. The simulations presented in section III-C were performed under this condition, although it is clear that the WTs in a WPP for various reasons may not always be in an operating point where such condition is satisfied. However, many measures do exist to keep the WT terminal voltage close to nominal, e.g. operation of the park transformer tap-changer, components for static or dynamic reactive power compensation, etc. Therefore, the authors consider it a reasonable assumption to perform the study at nominal WT terminal voltage. It is, however, clear that it is necessary to include the $\triangle Q$ POD in the operational planning and design of the WPP.

The time domain simulations showed that the WTs were capable of tightly following the received voltage reference to produce a collective WPP response as shown in Fig. 13 and 14. In the analyzed cases, the interaction between the WTs was not found to have any adverse impact on the ability of the WTs to respond to the commanded voltage reference. Prony analysis of the speed of a dominant generator showed that a positive damping contribution was achieved when adding the $\triangle Q$ POD to the WPP control. Time traces of generator speeds and results of the Prony analysis are shown in Fig. 12 and TABLE I, respectively.

\section{CONCLUSiON}

A reactive power, power oscillation damping control $(\Delta Q$ POD) requires that tight phase control of the modulated reactive power is possible. For a simple wind power plant (WPP) system, the induced phase shift at both WPP and wind turbine (WT) level was analyzed for frequencies of interest for power system oscillations. It was found that the analyzed elements all contribute to the resulting and not insignificant phase shift through the WPP and that they should be considered when phase compensation filters are designed for a $\Delta Q$ POD.

Next, such control was designed for a $150 \mathrm{WT}, 540 \mathrm{MW}$ WPP where all WTs were represented individually and the ability of the designed $\Delta Q$ POD to contribute to the damping of weakly damped dominant eigenvalues was demonstrated. Time domain simulations with the 150 WT WPP showed that a tight coordination between the WTs was possible such that the WTs contributed to a collective WPP response. The ability to produce a collective WPP response is very important, since a positive damping contribution necessitate a certain phase characteristic of the modulated reactive power as found from e.g. modal analysis. Prony analysis showed an increased damping of the dominant power system oscillations with the WPP $\triangle Q$ POD in operation.

\section{REFERENCES}

[1] E. Hagstrom, I. Norheim, and K. Uhlen, "Large-scale wind power integration in norway and impact on damping in the nordic grid," WIND ENERGY, vol. 8, no. 3, pp. 375-384, JUL-SEP 2005.
[2] J. Slootweg and W. Kling, "The impact of large scale wind power generation on power system oscillations," Electric Power Systems Research, vol. 67 , no. 1 , pp. $9-20,2003$.

[3] T. Knüppel, J. N. Nielsen, K. H. Jensen, A. Dixon, and J. Østergaard, "Small-signal stability of wind power system with full-load converter interfaced wind turbines," Accepted for publication by IET Renewable Power Generation, 2011

[4] G. Tsourakis, B. Nomikos, and C. Vournas, "Effect of wind parks with doubly fed asynchronous generators on small-signal stability," Electric Power Systems Research, vol. 79, no. 1, pp. 190 - 200, 2009. [Online]. Available: http://www.sciencedirect.com/science/article/ B6V30-4T0FHRM-1/2/3b6ac71f22cac8ff81670dcc6944a0f9

[5] T. Knüppel, J. N. Nielsen, K. H. Jensen, A. Dixon, and J. Østergaard, "Power oscillation damping controller for wind power plant utilizing wind turbine inertia as energy storage," in 2011 IEEE PES General Meeting. Detroit, MI, USA: IEEE Power \& Energy Society, July 2011, pp. 1-8, iSBN: 978-1-4577-1001-8.

[6] K. Elkington, "Modelling and control of doubly fed induction generators in power systems: Towards understanding the impact of large wind parks on power system stability," PhD Thesis, KTH, Electric Power Systems, SE-100 44, Stockholm, Sweden, April 2009, ISBN: 978-917415-264-7. [Online]. Available: http://urn.kb.se/resolve?urn=urn:nbn: se:kth:diva- 10206

[7] F. Hughes, O. Anaya-Lara, N. Jenkins, and G. Strbac, "A power system stabilizer for dfig-based wind generation," Power System, IEEE Transactions on, vol. 21, no. 2, pp. 763-772, 2006.

[8] L. Fan, H. Yin, and Z. Miao, "On active/reactive power modulation of dfig-based wind generation for interarea oscillation damping," Energy Conversion, IEEE Transactions on, vol. 26, no. 2, pp. 513 -521, June 2011.

[9] G. Tsourakis, B. Nomikos, and C. Vournas, "Contribution of doubly fed wind generators to oscillation damping," Energy Conversion, IEEE Transactions on, vol. 24, no. 3, pp. 783 -791, Sept. 2009.

[10] D. Gautam, V. Vittal, R. Ayyanar, and T. Harbour, "Supplementary control for damping power oscillations due to increased penetration of doubly fed induction generators in large power systems," in 2011 IEEE/PES Power Systems Conference and Exposition (PSCE 2011). Department of Electrical Engineering Arizona State University Tempe, AZ 85287, 2011, pp. 1 - 6, ISBN: 9781612847870.

[11] A. Adamczyk, R. Teodorescu, and P. Rodriguez, "Control of full-scale converter based wind power plants for damping of low frequency system oscillations," in PowerTech, 2011 IEEE Trondheim, June 2011, pp. 1-7.

[12] R. Fernandez, R. Mantz, and P. Battaiotto, "Contribution of wind farms to the network stability," in Power Engineering Society General Meeting, 2006. IEEE, 2006, pp. 1-6.

[13] D. Gautam, L. Goel, R. Ayyanar, V. Vittal, and T. Harbour, "Control strategy to mitigate the impact of reduced inertia due to doubly fed induction generators on large power systems," Power Systems, IEEE Transactions on, vol. 26, no. 1, pp. 214 -224, Feb 2011.

[14] T. Knüppel, J. N. Nielsen, K. H. Jensen, A. Dixon, and J. Østergaard, "Power oscillation damping capabilities of wind power plant with full converter wind turbines considering its distributed and modular characteristics," in Proceedings of IET Renewable Power Generation Conference 2011, The Institution of Engineering and Technology. Radisson Blu, Edinburgh, UK: IET RPG, September 2011.

[15] G. Rogers, Power System Oscillations, 1st ed., ser. Power Electronics and Power Systems. Kluwer Academic Publishers, 2000, ISBN-10: 0792377125 .

[16] M. Lahtinen, T. Rauhala, H. Kuisti, J. Peltola, and P. Halonen, "Static var compensator enhancing the operational reliability of finnish transmission network," in Proceedings of CIGRE Session 2010, Paris, France, August 2010, paper B4-206.

[17] S. Ray, B. Chaudhuri, and R. Majumder, "Appropriate signal selection for damping multi-modal oscillations using low order controllers," in Power and Energy Society General Meeting - Conversion and Delivery of Electrical Energy in the 21st Century, 2008 IEEE, July 2008, pp. 1 -7 .

[18] N. Mithulananthan, C. Canizares, J. Reeve, and G. Rogers, "Comparison of pss, svc, and statcom controllers for damping power system oscillations," Power Systems, IEEE Transactions on, vol. 18, no. 2, pp. 786 792, May 2003.

[19] E. Larsen, J. Sanchez-Gasca, and J. Chow, "Concepts for design of facts controllers to damp power swings," Power Systems, IEEE Transactions on, vol. 10, no. 2, pp. 948-956, May 1995.

[20] S. Wang, J. Chow, K. Minto, and R. Rajamani, "Low-order controller design for model matching optimization using coprime factors and lmi," 
in American Control Conference, 1999. Proceedings of the 1999, vol. 3 , 1999, pp. $1871-1875$ vol.3.

[21] R. Ramos, L. Alberto, and N. Bretas, "A new methodology for the coordinated design of robust decentralized power system damping controllers," Power Systems, IEEE Transactions on, vol. 19, no. 1, pp. $444-454$, Feb. 2004

[22] A. R. Messina, O. Begovich, J. H. López, and E. N. Reyes, "Design of multiple facts controllers for damping inter-area oscillations: a decentralised control approach," International Journal of Electrical Power \& Energy Systems, vol. 26, no. 1, pp. 19 - 29, 2004. [Online]. Available: http://www.sciencedirect.com/science/article/ B6V2T-49DN6VC-1/2/ab5a3d7c05115434bad4c6a5453df94c

[23] N. R. Chaudhuri, S. Ray, R. Majumder, and B. Chaudhuri, "A new approach to continuous latency compensation with adaptive phasor power oscillation damping controller (pod)," Power Systems, IEEE Transactions on, vol. 25, no. 2, pp. 939 -946, May 2010.

[24] L. Fan, "Review of robust feedback control applications in power systems," in Power Systems Conference and Exposition, 2009. PSCE 'O9. IEEE/PES, March 2009, pp. 1-7.

[25] E. Lerch, D. Povh, and L. Xu, "Advanced svc control for damping power system oscillations," Power Systems, IEEE Transactions on, vol. 6, no. 2, pp. $524-535$, May 1991.

[26] H. Nguyen-Duc, L.-A. Dessaint, A. F. Okou, and I. Kamwa, "A power oscillation damping control scheme based on bang-bang modulation of facts signals," Power Systems, IEEE Transactions on, vol. 25, no. 4, pp. 1918-1927, Nov. 2010.

[27] J. N. Nielsen, V. Akhmatov, J. Thisted, E. Grøndahl, P. Egedal, M. N. Frydensbjerg, and K. H. Jensen, "Modelling and fault-ride-trough tests of Siemens Wind Power 3.6 MW variable-speed wind turbines," Wind Engineering, vol. 31, pp. 441-452(12), December 2007.

[28] N. G. plc, "The grid code," National Grid Electricity Transmission plc, National Grid House, Warwick Technology Park, Gallows Hill, Warwick, CV34 6DA, UK, Tech. Rep. Issue 4 Revision 2, March 2010.

[29] X. Lei, E. Lerch, D. Povh, and O. Ruhle, "A large integrated power system software package-netomac," in Power System Technology, 1998. Proceedings. POWERCON '98. 1998 International Conference on, vol. 1, Aug. 1998, pp. $17-22$ vol.1.

[30] M. Gibbard and D. Vowles, "Simplified 14-generator model of the SE Australian power system," School of Electrical \& Electronic Engineering, The University of Adelaide, South Australia, Tech. Rep. 2, May 2008. [Online]. Available: http://www.eleceng.adelaide. edu.au/Groups/PCON/PowerSystems/IEEE/BenchmarkData/index.html 